\title{
Splicing analysis of CYP11B1 mutation in a family affected with $11 \beta$-hydroxylase deficiency: case report
}

\author{
Pattaranatcha Charnwichai ${ }^{1,2}$, Patra Yeetong ${ }^{2,3}$, Kanya Suphapeetiporn ${ }^{2,4}$, Vichit Supornsilchai ${ }^{5}$, \\ Taninee Sahakitrungruang ${ }^{5^{*}}$ and Vorasuk Shotelersuk $k^{2,4}$
}

\begin{abstract}
Background: Congenital adrenal hyperplasia (CAH) due to steroid $11 \beta$-hydroxylase deficiency $(11 \beta-O H D)$ is a rare form of CAH associated with low renin hypertension, hypokalemia, hyperandrogenemia and ambiguous genitalia in affected females. Herein we describe the clinical, hormonal and molecular characteristics of two Uzbekistan siblings with $11 \beta-O H D$ and analyze the effects of a splicing mutation.

Case presentation: A 46,XX girl presented with genital ambiguity and low renin hypertension; her 46,XY brother presented with precocious puberty. Hormonal studies suggested $11 \beta-O H D$. Mutation analysis was performed by PCR followed by Sanger sequencing of the entire coding regions and their flanking introns of the CYP11B1 gene. Mutation analysis showed that both patients were compound heterozygous for IVS7 + $\mathrm{G}>\mathrm{A}$, and c.421C > T. Although the identified mutations have been previously described, this is, to our knowledge, the first report of these mutations in compound heterozygotes. A minigene assay was used to determine the effects of the splicing mutation. The constructs containing either the wild-type or the splice-site mutant CYP11B1 genomic DNA of exons-introns 6-9 were transfected into COS-7 cells; subsequently, RNA splicing was assessed by reversed transcribed-PCR of CYP11B1 complementary DNA. The minigene assay revealed that the IVS7 + IG > A mutation resulted in two shorter incorrectly spliced products; one skipping the exon 7 and the other skipping the exons 7-8. The c.421C > T mutation leads to the introduction of a premature stop codon at residue 141 (p.R141X). These mutations are expected to code non-functional proteins.
\end{abstract}

Conclusion: Compound heterozygous mutations (IVS7 + 1G > A and p.R141X) in the CYP11B1 gene were found to cause $11 \beta-O H D$. The IVS7 + 1G > A mutation causes aberrant splicing of CYP11B1 leading to exon skipping. This finding could facilitate the future novel therapies targeted on splicing modulation to treat human disease.

Keywords: CYP11B1, Splicing, Mutation, 11ß-hydroxylase deficiency, Congenital adrenal hyperplasia, Case report

\section{Background}

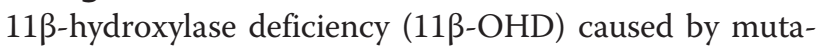
tions in the CYP11B1 gene accounts for approximately $5-8 \%$ of congenital adrenal hyperplasia (CAH) in nonconsanguineous populations, but accounts for $\sim 15 \%$ of cases in both Muslim and Jewish Middle Eastern popula-

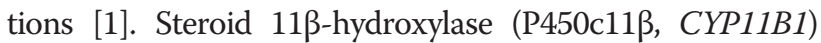
converts 11-deoxycortisol to cortisol, representing the final step in cortisol biosynthesis, and 11-deoxycorticosterone

\footnotetext{
* Correspondence: Taninee.P@chula.ac.th

${ }^{5}$ Division of Pediatric Endocrinology, Department of Pediatrics, Faculty of

Medicine, Chulalongkorn University, Bangkok 10330, Thailand

Full list of author information is available at the end of the article
}

(DOC) to corticosterone. Thus, deficient P450c11 $\beta$ activity results in impaired cortisol synthesis and accumulation of 11-deoxycortisol and the mineralocorticoid precursor DOC, which leads to significant hypertension, a hallmark feature of this CAH variant [1]. Accumulated steroid precursors are shunted into the androgen synthesis pathway, leading to androgen excess. Classic $11 \beta-O H D$ results in virilization of the external genitalia in affected females (46,XX disorders of sex development) as well as precocious puberty, accelerated growth and bone maturation in both sexes. Patients with $11 \beta-O H D$ can have elevated concentrations of 17-hydroxyprogesterone (17OHP), which accumulates two steps behind the enzymatic block, so that $11 \beta$ - 
OHD may be detected by $17 \mathrm{OHP}$ newborn screening program [2]. The diagnosis is established by elevated basal concentrations of DOC and 11-deoxycortisol, which hyper respond to $\mathrm{ACTH}$ stimulation.

CYP11B1 is located on the long arm of chromosome 8 (8q21), consisting of 9 exons, and encodes 503 amino acids. To date, over 80 mutations in CYP11B1 gene are described. Most are missense and nonsense mutations, but splice-site mutations, small or gross deletions/insertions, and complex rearrangements with CYP11B2 have also been identified [3-5]. The majority of CYP11B1 mutations are associated with classic $11 \beta-\mathrm{OHD}$, and only a few mutations causing non-classic $11 \beta-O H D$ which can manifest later in otherwise asymptomatic women with hirsutism, and menstrual irregularities $[6,7]$.

In this report, we describe two siblings with the clinical and hormonal phenotypes of $11 \beta-\mathrm{OHD}$ and identified compound heterozygous mutations in the CYP11B1 gene. The splicing mutation was studied in vitro for its functional consequences with a minigene experiment and showed exon-skipping which confirmed the clinical diagnosis.

\section{Case presentation}

The patients were siblings from a non-consanguineous Uzbekistan family. Patient 1 was a 3-yr-old 46,XX female with ambiguous genitalia. She was previously evaluated for her abnormal genital development and underwent first genital surgery in Turkey. On an initial evaluation at age 2 y $8 \mathrm{~m}$, her height was $100 \mathrm{~cm}(+2.1 \mathrm{SD})$, her weight was $15.8 \mathrm{~kg},(+1.4 \mathrm{SD})$, blood pressure (BP) was $110 / 70 \mathrm{mmHg}$ $\left(94^{\text {th }} / 96^{\text {th }}\right.$ percentiles). The physical examination revealed that the phallus was $5 \mathrm{~cm}$ long and $2 \mathrm{~cm}$ wide (Prader grade IV); no gonads were palpable in the inguinal region. The areola and palmar creases were pigmented bilaterally. An ACTH stimulation test $(250 \mu \mathrm{g})$ showed grossly elevated baseline ACTH $(238 \mathrm{pg} / \mathrm{mL})$ and basal cortisol of $4.7 \mu \mathrm{g} / \mathrm{dL}$ with non-response to $\mathrm{ACTH}$ and moderately elevated progesterone and 17OHP after $60 \mathrm{~min}$; 11-deoxycortisol and androstenedione concentrations were markedly high (Table 1). The serum sodium was $136 \mathrm{mmol} / \mathrm{L}$, potassium
$3.1 \mathrm{mmol} / \mathrm{L}$, plasma renin activity (PRA) was very low at $15 \mathrm{ng} / \mathrm{dL} / \mathrm{h}$ (nl, 171-1115), and aldosterone $2 \mathrm{ng} / \mathrm{dL}$ (nl, 3-35). Her total testosterone levels were $132 \mathrm{ng} / \mathrm{dL}$ (nl, $<3-10)$ and dehydroepiandrosterone sulfate (DHEAS) $165.2 \mu \mathrm{g} / \mathrm{dL}$ (nl, <5-57). She was followed up at the King Chulalongkorn Memorial Hospital (Bangkok, Thailand) due to the family relocation at age $3 \mathrm{yr}$ for further management. After receiving the results of an ACTH stimulation test, she was started treatment with hydrocortisone, $5 \mathrm{mg}$ thrice daily $\left(10 \mathrm{mg} / \mathrm{m}^{2} / \mathrm{d}\right)$ which improved BP into the normal range $(90 / 60 \mathrm{mmHg})$, suppressed testosterone, and PRA became measurable (200-496 ng/dL/h).

Patient 2 is the younger brother of Patient 1 . He presented at 2 years of age with acne and masculinization (isosexual precocious puberty). Physical examination revealed an advanced maturation of external genitalia as well as a low-pitched voice. His Tanner stages were G3 and $\mathrm{PH} 1$, and each of his testes was $3 \mathrm{~mL}$ in volume. His height was $97 \mathrm{~cm}(+3.2 \mathrm{SD})$ and weight was $17 \mathrm{~kg}$ (+2.9 SD). Height gain was accelerated from 12-monthold on the growth chart (from +2.6 SD to +3.2 SD). Skin pigmentation appeared consistent with his ethnicity, but no evident mucosal pigmentation. His BP was 110/ $65 \mathrm{mmHg}\left(92^{\text {th }} / 95^{\text {th }}\right.$ percentiles). Labs revealed serum $\mathrm{Na} 136 \mathrm{mmol} / \mathrm{L}, \mathrm{K} 4.3 \mathrm{mmol} / \mathrm{L}$, bicarbonate $24 \mathrm{mmol} / \mathrm{L}$, BUN 12 and $\mathrm{Cr} 0.3 \mathrm{mg} / \mathrm{dL}$, respectively. An ACTH stimulation test showed elevated baseline ACTH, a low basal cortisol $(2.3 \mu \mathrm{g} / \mathrm{dL})$ with non-response to ACTH and moderately elevated $17 \mathrm{OHP}$ after $60 \mathrm{~min}$ (Table 1). 11-deoxycortisol concentrations were not measured. PRA was low at $106 \mathrm{ng} / \mathrm{dL} / \mathrm{h}$ (nl, 171-1115), and low aldosterone $0.2 \mathrm{ng} / \mathrm{dL}$ (nl, 3-35). He was then treated with hydrocortisone $2.5 \mathrm{mg}$ thrice daily $\left(11 \mathrm{mg} / \mathrm{m}^{2} / \mathrm{d}\right)$. His blood pressure was well controlled, and PRA was increased up to $738 \mathrm{ng} / \mathrm{dL} / \mathrm{h}$.

\section{DNA sequencing}

Genomic DNA from peripheral blood leucocytes of the patients and their parents was extracted by using the QIAamp ${ }^{\circ}$ DNA Blood Mini Kit (Qiagen, Valencia, CA) after taking informed consent. The coding sequence of

Table 1 Basal and 60 min post ACTH $(250 \mu \mathrm{g})$ stimulated adrenal steroid profile

\begin{tabular}{|c|c|c|c|c|c|c|}
\hline \multirow[t]{3}{*}{ Steroids } & \multicolumn{2}{|c|}{ Patient 1} & \multicolumn{2}{|c|}{ Patient 2} & \multicolumn{2}{|c|}{ Reference values } \\
\hline & \multicolumn{2}{|c|}{ (age 2 y 8 m) } & \multicolumn{2}{|c|}{ (age 2 y) } & \multirow[b]{2}{*}{ Basal } & \multirow[b]{2}{*}{ Stimulated } \\
\hline & Basal & Stimulated & Basal & Stimulated & & \\
\hline ACTH $(\mathrm{pg} / \mathrm{mL})$ & 238 & - & 150 & - & $10-65$ & - \\
\hline Cortisol ( $\mu \mathrm{g} / \mathrm{dL})$ & 4.72 & 4.65 & 2.3 & 2.3 & $3-22$ & $27-50$ \\
\hline 17-OHP (ng/dL) & 2880 & 2730 & 1310 & 2380 & $13-173$ & $85-250$ \\
\hline Progesterone (ng/dL) & 464 & 499 & - & - & a & a \\
\hline Androstenedione (ng/dL) & 2750 & 2710 & - & - & $<10-48$ & $<10-87$ \\
\hline 11-deoxycortisol (ng/dL) & 15100 & - & - & - & $7-210$ & $95-323$ \\
\hline
\end{tabular}

${ }^{a}$ Note: Reference values are unavailable 
CYP11B1 gene including exon-intron boundaries was amplified in eight fragments using specific primers (Table 2). PCR products were treated with ExoSAP-IT (USP Corporation, Cleveland, $\mathrm{OH}$ ), and sent for direct sequencing at Macrogen Inc. (Seoul, Korea). Analyses were performed by Sequencher 4.2 (Gene Codes Corporation, Ann Arbor, MI).

\section{Minigene construction and splicing analysis}

We performed a minigene in vitro experiment of the CYP11B1 splicing mutation. A segment of the wild-type (WT) and mutant (IVS7 + 1G > A) genomic DNA (gDNA) of CYP11B1 gene consisting of exons 6 to 9 and their inbetween introns was amplified by PCR using the oligonucleotides listed in Table 2. We used the gDNA of a normal control and the patient with IVS7 + 1G > A CYP11B1 mutation as a template of minigene constructs. PCR reactions were carried out in a $20 \mu \mathrm{l}$ volume containing $50 \mathrm{ng}$ gDNA, 10xPCR buffer, $25 \mathrm{mM} \mathrm{MgCl} 2,10 \mu \mathrm{M}$ dNTPs, 5 $\mathrm{U} / \mu \mathrm{l}$ Taq polymerase and $10 \mu \mathrm{M}$ of each primer, using the following parameters: $30 \mathrm{~s}$ at $94{ }^{\circ} \mathrm{C}, 30 \mathrm{~s}$ at $60{ }^{\circ} \mathrm{C}$ and $1.30 \mathrm{~min}$ at $72{ }^{\circ} \mathrm{C}$. The PCR product was cleaved with BamHI-HF and XbaI enzymes and cloned into the corresponding sites of pcDNA $^{\text {tw }} 3.1 /$ myc-His B mammalian expression vector (Invitrogen, Carlsbad, CA) using T4 DNA ligase (New England BioLabs, UK). The wild-type and mutant vectors were confirmed by direct sequencing using NCBI Reference Sequences (RefSeq) NG_007954.1 as the genomic reference and NM_000497.3 as the mRNA reference.

COS-7 cells were cultured in Dulbecco's Modified Eagles Medium, High Glucose (HyClone Laboratories, Logan, UT) supplemented with $10 \%$ fetal bovine serum (SigmaAldrich, Singapore) and $0.01 \%$ penicillin/streptomycin (HyClone Laboratories) at $37{ }^{\circ} \mathrm{C}$ in a humidified $5 \% \mathrm{CO}_{2}$ incubator. Cells were grown on 6-well plates and transiently transfected with the wild-type and mutant minigene constructs $(1 \mu \mathrm{g})$ using Effectene ${ }^{\ominus}$ Transfection Reagent (Qiagen). Cells incubated for $48 \mathrm{~h}$ after transfection and then were washed 3 times with PBS and kept frozen at $-20{ }^{\circ} \mathrm{C}$. Total cellular RNA was extracted using QIAamp ${ }^{\circ}$ RNA Blood Mini Kit (Qiagen) and treated with DNaseI (Qiagen). The RNAs were then used as template for cDNA synthesis using ImProm-II ${ }^{\mathrm{Im}}$ Reverse Transcription System (Promega Corporation, Madison, WI). Finally, both the WT and mutant cDNAs were amplified by PCR using the same primers and conditions as used for the minigene construction. The PCR products were analyzed by electrophoresis on a $1 \%$ agarose gel followed by staining with ethidium bromide. Each PCR product was confirmed by Sanger sequencing after subcloning into $\mathrm{pGEM}^{\circ}$-T Easy vectors (Promega).

\section{Results}

\section{Mutation analysis}

DNA sequencing of the entire coding regions and their flanking introns of the CYP11B1 gene showed that both siblings were compound heterozygous for a nonsense mutation c.421C > T in its exon 3 (NCBI RefSeq NG_007954.1), causing the introduction of a premature stop codon at residue 141 (p.R141X); and a splice site mutation, c.1200 + $1 \mathrm{G}>\mathrm{A}$ which is at the 5 donor splice site of the intron 7 (IVS7 + 1G > A). These identified mutations were reported previously [8-10], but their pathogenic mechanisms have not clearly been elucidated. Sequence analysis of the parental gDNA demonstrated that the mother was heterozygous for the c.421C $>\mathrm{T}$ mutation and the father, heterozygous for the c. $1200+1 G>$ A mutation (Fig. 1).

\section{Minigene analysis of the splice site mutation}

We hypothesized that the c. $1200+1 \mathrm{G}>\mathrm{A}$ (IVS7 + 1G > A) mutation located at the splicing donor site of intron 7 would create an abnormal splicing of the mRNA. To examine this possibility, we constructed expression vectors containing the WT and the mutant c. $1200+1 G>A$ CYP11B1 minigene sequence from exons 6 to 9 (Fig. 2a). The resultant minigenes were transfected into COS-7 cells. Then, total RNA was isolated and analyzed by the RT-PCR method. We found that the mutant c.1200+1G > A CYP11B1 minigene was processed to two major incorrectly spliced products which were shorter than the WT minigene (Fig. 2b). Sequence analysis of the RT-PCR products after subcloning into $\mathrm{PGEM}^{\ominus}$-T Easy vector revealed that one of the mutant

Table 2 Sequences of oligonucleotide primers used for PCR amplification and minigene construction

\begin{tabular}{|c|c|c|}
\hline Primer & Sense Strand & Antisense Strand \\
\hline CYP11B1_Exon 1 & 5'- GTTCTCCCATGACGTGATCCCTCT - 3' & 5'- TCCAAAGGATGCAGAGTGCC - 3' \\
\hline CYP11B1_Exon 2 & $5^{\prime}$ - TGGACAGGAGACACTTTGGAT - 3' & $5^{\prime}-$ TCGCCGCTTACAGCAAGAAC - 3' \\
\hline CYP11B1_Exon 3-4 & $5^{\prime}-$ TGGGGACAAGGAGGATGGGATAC - 3' & $5^{\prime}-$ TGGTGGAGAGGGAGAAATTGGG - 3' \\
\hline CYP11B1_Exon 4 & $5^{\prime}-$ CGTGGGAAGATCCAGCCTCAG - 3' & $5^{\prime}-$ GGAAGGTGAGGAATCCCCGAC - 3' \\
\hline CYP11B1_Exon 5 & $5^{\prime}-$ AGGAGGAGGACACTGAAGGATG - 3' & $5^{\prime}-$ AGGCAGGCTTGGCATCACC - 3' \\
\hline CYP11B1_Exon 6 & 5' - GGCTCTGTCGTTCTCAGGGTATGC - 3' & $5^{\prime}$ - GGCGTTGAAGAGGGATTCCAGAG - 3' \\
\hline $\begin{array}{l}\text { CYP11B1_Exon 7-8 } \\
\text { CYP11B1_Exon 9 } \\
\text { CYP11B1_IVS7_construct }\end{array}$ & $\begin{array}{l}5^{\prime}-\text { AGAGAGCACAGGAAGCCCCATC - 3' } \\
5^{\prime}-\text { GTTCCCCCTTCAGCATAATCTC - 3' } \\
5^{\prime}-\text { AGTCGGATCCCTTGCTGATGACGCTCTTG - 3' }\end{array}$ & $\begin{array}{l}5^{\prime}-\text { CAGTCCCACATTGCTCAAGC - 3' } \\
5^{\prime}-\text { GCCCTCGGGAGTTCCATIT - 3' } \\
5^{\prime}-\text { GTACTCTAGAATGGCTCTGAAGGTGAGGAG - 3' }\end{array}$ \\
\hline
\end{tabular}




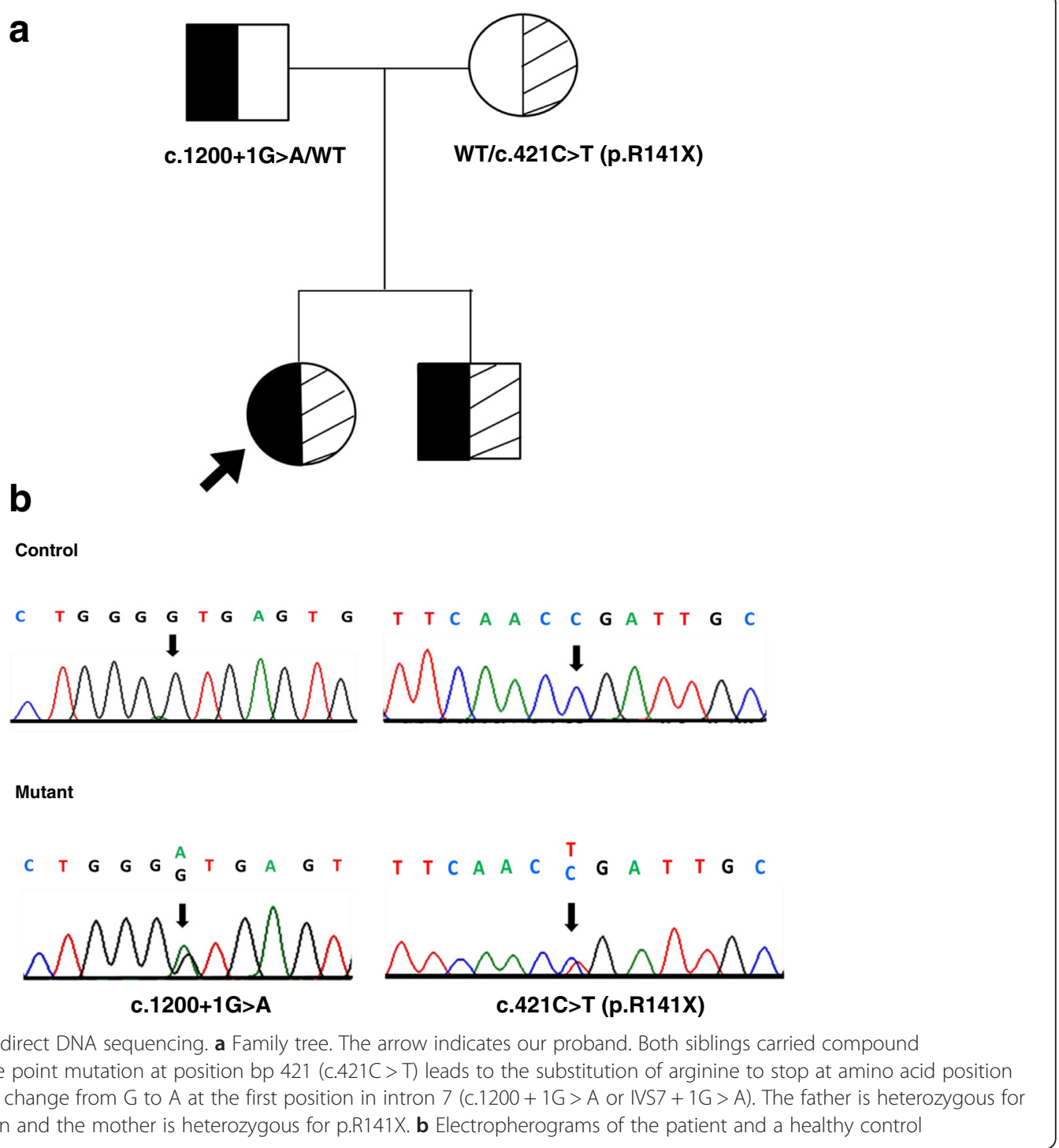

fragments skipped the entire exon 7 , while containing the full-length sequences of exons 6, 8, 9. The other mutant PCR product skipped the exons 7 and 8 , while retaining full-length sequences of exons 6 and 9 (Fig. 2c).

\section{Discussion}

In this study, we have described two severe CYP11B1 mutations found in two siblings diagnosed with classic $11 \beta$ $\mathrm{OHD}$ in a family from Uzbekistan. Virilization and hypertension are the main clinical features of the classic $11 \beta$ OHD. Despite inability of aldosterone synthesis, overproduction of DOC, which is a less potent mineralocorticoid, causes salt retention and hypertension. However, affected newborns may have mild, transient salt loss presumably due to relatively high mineralocorticoids resistance in the newborn period [11]. Signs of mineralocorticoid excess generally correlate poorly with the degree of virilization in affected girls [3]. Blood pressure is usually normal during infancy and hypertension is often identified later in toddlerhood or in childhood, although its presence in infancy was demonstrated [12].

Most of the CYP11B1 mutations described to date result in the classic form of $11 \beta-O H D$. Unlike 21hydroxylase deficiency, molecular-genetic studies of $11 \beta$ OHD are relatively fewer, and a number of identified CYP11B1 mutations have not been functionally characterized [5, 13]. Therefore, the exact genotype-phenotype prediction of $11 \beta-O H D$ has not been well established. Previous studies showed that in vitro activities less than $5 \%$ were considered severe and consistent with classic $11 \beta$-OHD $[5,13]$. In this present study, we describe two siblings suffering from classic $11 \beta-O H D$ who were compound heterozygous for a nonsense and a splice-site CYP11B1 mutations. The nonsense p. R141X is expected 


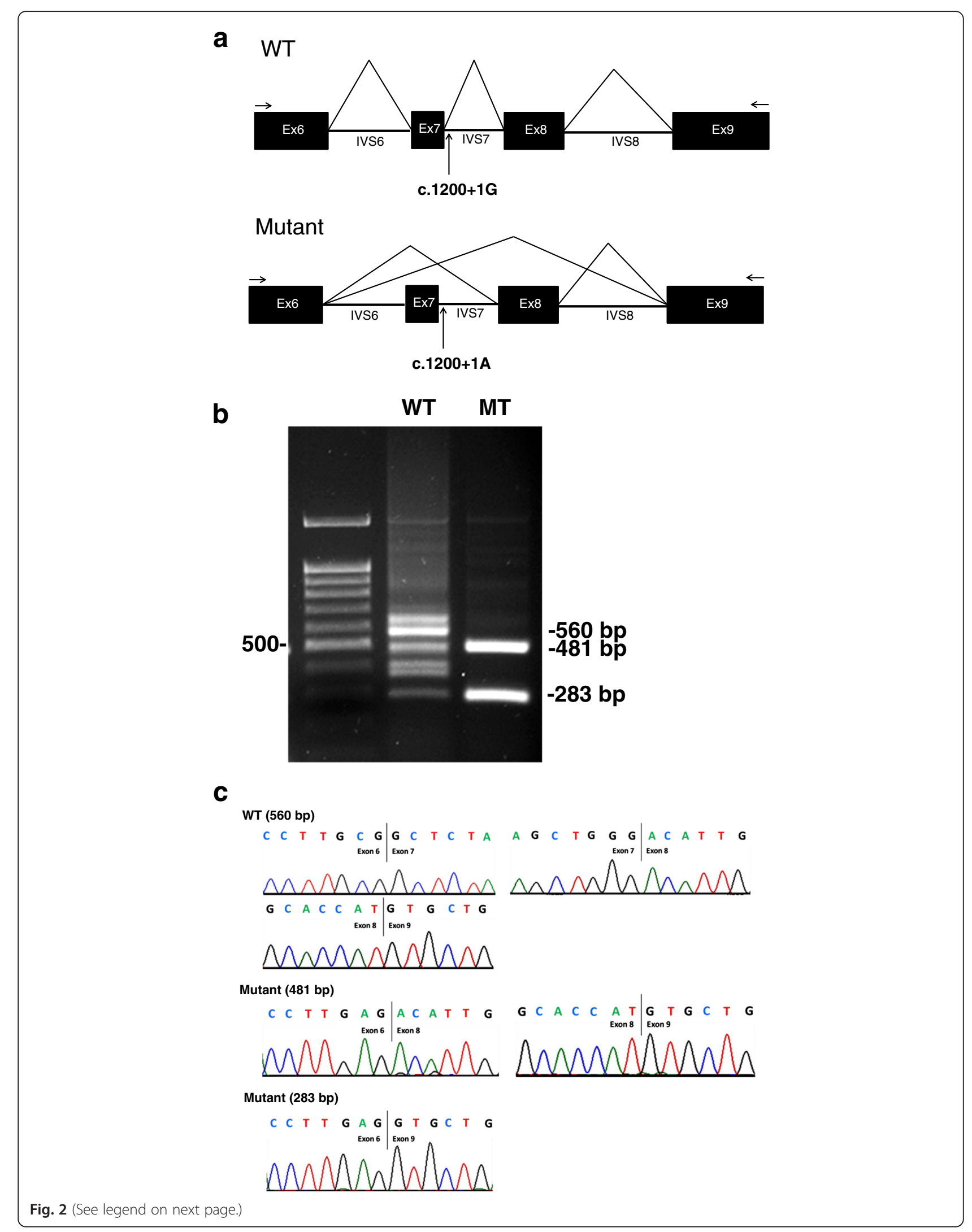


(See figure on previous page.)

Fig. 2 Minigene experiment. a The scheme shows the set-up of the minigene constructs for the splicing analysis in the WT and mutant expression vectors containing c.1200 + 1G > A mutation (arrows). b COS-7 cells were transfected with the wild-type (WT) or mutant (MT) minigene constructs. Total RNA from the transfected cells were used for RT-PCR of CYP11B1 CDNA. The figure shows the expected 560-bp PCR product from the WT construct and two shorter incorrectly spliced products from the mutant, sized 481 and 283 bp on an agarose gel. c Electropherograms of the minigene PCR products. The 481 bp mutant fragments skipped the entire exon 7, while containing the full-length sequences of exons 6, 8, 9. The 283 bp mutant PCR product skipped the exons 7 and 8, while retaining full-length sequences of exons 6 and 9. Black lines indicated exon-exon boundaries

to lead to a premature stop in the exon 3 and yields a truncated enzyme lacking the essential residues for heme binding domain, consistent with our patients' clinical phenotypes and near-completely abolished in vitro CYP11B1 activity in a recent study [14].

In addition, we identified a previously described IVS7 + $1 G>A$ mutation in CYP11B1 affecting the consensus slice donor site of the exon 7. The minigene experiment confirmed that this splice site mutation caused exon skipping (either a complete loss of the exon 7 or both exons 7 and 8). Most reported CYP11B1 mutations are located in exons 6,7 , and 8 and $70 \%$ of amino acid sequences in these exons are identical in human, ox, rat, and mouse, suggesting that exons 6-8 are essential for the enzymatic activity of CYP11B1 [15]. Recently, Nguyen et al. [9] studied a minigene experiment of this same mutation. Nonetheless, the authors designed a shorter minigene construct which had only exon 7 , intron 7 , and exon 8 . They found that the IVS7 + 1G > A mutation caused an intron retention.

Splicing errors are well recognized causes of genetic diseases. Previous data point to an estimated frequency of sequence variations affect pre-mRNA splicing up to $50 \%$ of the alleles causing human disease $[16,17]$. Splice site nucleotide substitutions may result in skipping of the involved exon, intron retention, creation of a pseudo-exon within intron, usage of a cryptic splice site, or a combination of several of these $[18,19]$. Hence, the design of minigene constructs is important to correctly identify the splicing effect of specific splice site mutations. Recent data have suggested that cassette exon skipping is the most common alternative splicing event in humans $[19,20]$. To date, a $+1 \mathrm{G}>$ A substitution at the 5'-splice donor site has been identified in a number of human diseases [21]. Functional studies of other $+1 \mathrm{G}>\mathrm{A}$ 5'-splice site mutations have shown either recognition of a 5'-cryptic splice site or exon skipping [22]. Therefore, we have designed the minigene constructs including exons 6-9 and introns 6-8 and our results confirmed that the IVS7 + 1G > A mutant construct results in exon skipping. To date, the therapies to modulate RNA mis-splicing using antisense oligonucleotide or small molecules are emerging [19]. The understanding of definite genetic mechanism could expand opportunities for gene therapy. Modulation of aberrant splicing transcripts can become a novel therapeutic approach for many diseases caused by splice site defects.

\section{Conclusions}

In summary, we describe two compound heterozygous CYP11B1 mutations that severely affect normal protein structure explaining a severe phenotype of classic 11 $\beta$ hydroxylase deficiency. Our findings suggest the mutation IVS7 + 1G > A causes aberrant splicing of CYP11B1 leading to exon skipping. Our findings may help for better understanding of splice site mutation mechanism and facilitate the future new therapies targeted on splicing modulation to treat human disease.

\section{Abbreviations \\ 11ß-OHD, 11ß-hydroxylase deficiency; 17OHP, 17-hydroxyprogesterone; ACTH, adrenocorticotropic hormone; $\mathrm{CAH}$, congenital adrenal hyperplasia; DHEAS, dehydroepiandrosterone sulfate; DOC, 11-deoxycorticosterone; gDNA, genomic DNA; mRNA, messenger RNA; MT, mutant; nl, normal; PCR, polymerase chain reaction; PRA, plasma renin activity; RT-PCR, reverse transcription polymerase chain reaction; WT, wild-type}

\section{Funding}

This study was supported by the Thailand Research Fund grant no.RSA5780054 (to T.S.), RTA56800003 (to V.S.), and the Chulalongkorn Academic Advancement into Its $2^{\text {nd }}$ Century Project. P.C. was supported by the scholarship from the Graduate Scholarship to commemorate the $72^{\text {nd }}$ Anniversary of His Majesty King Bhumibol Adulyadej, Chulalongkorn University.

\section{Availability of data and materials}

All data contained within the article.

\section{Authors' contributions}

PC carried out the molecular genetic studies and drafted the manuscript. The patients were under the care of $\mathrm{VS}^{5}$. TS conceived the idea of the report and drafted the manuscript. PY, KS, TS, and $\mathrm{VS}^{2}$ participated in the writing, review of the literature, text editing and finalization of the manuscript. All authors read and approved the final manuscript.

\section{Competing interests}

The authors declare that they have no competing interests.

\section{Consent for publication}

Written informed consent was obtained from the patient's parent for publication of this Case report and any accompanying images. A copy of the written consent is available for review by the Editor of this journal.

\section{Ethics approval and consent to participate}

All procedures were performed according to the Declaration of Helsinki and approved by the Ethics Committee, Faculty of Medicine, Chulalongkorn University. Written informed consent was obtained from the patient's parent for participate in this study.

\section{Author details}

'Department of Bioscience, Faculty of Science, Chulalongkorn University, Bangkok 10330, Thailand. ${ }^{2}$ Excellence Center for Medical Genetics, Department of Pediatrics, Faculty of Medicine, Chulalongkorn University, Bangkok 10330, Thailand. ${ }^{3}$ Department of Botany, Faculty of Science, Chulalongkorn University, Bangkok 10330, Thailand. ${ }^{4}$ Center of Excellence for 
Medical Genetics, King Chulalongkorn Memorial Hospital, Bangkok 10330, Thailand. ${ }^{5}$ Division of Pediatric Endocrinology, Department of Pediatrics, Faculty of Medicine, Chulalongkorn University, Bangkok 10330, Thailand

Received: 17 February 2016 Accepted: 6 June 2016

Published online: 17 June 2016

\section{References}

1. Miller WL, Auchus RJ. The molecular biology, biochemistry, and physiology of human steroidogenesis and its disorders. Endocr Rev. 2011;32:81-151.

2. Peter M, Janzen N, Sander S, Korsch E, Riepe FG, Sander J. A case of $11 \beta$ hydroxylase deficiency detected in a newborn screening program by second-tier LC-MS/MS. Horm Res. 2008:69:253-6.

3. Nimkarn S, New MI. Steroid 11ß-hydroxylase deficiency congenital adrenal hyperplasia. Trends Endocrinol Metab. 2008;19:96-9.

4. Zhu YS, Cordero JJ, Can S, Cai LQ, You X, Herrera C, et al. Mutations in CYP11B1 gene: phenotype-genotype correlations. Am J Med Genet A. 2003; 122A:193-200

5. Zhao LQ, Han S, Tian HM. Progress in molecular-genetic studies on congenital adrenal hyperplasia due to $11 \beta$-hydroxylase deficiency. World J Pediatr. 2008;4:85-90.

6. Joehrer K, Geley S, Strasser-Wozak EM, Azziz R, Wollmann HA, Schmitt K, et al. CYP11B1 mutations causing nonclassic adrenal hyperplasia due to $11 \beta$ hydroxylase deficiency. Hum Mol Genet. 1997;6:1829-34.

7. Reisch N, Högler W, Parajes S, Rose IT, Dhir V, Götzinger J, et al. A diagnosis not to be missed: nonclassic steroid 11ß-hydroxylase deficiency presenting with premature adrenarche and hirsutism. J Clin Endocrinol Metab. 2013;98:E1620-25.

8. Matsubara K, Kataoka N, Ogita S, Sano S, Ogata T, Fukami M, et al. Uniparental disomy of chromosome 8 leading to homozygosity of a CYP11B1 mutation in a patient with congenital adrenal hyperplasia: implication for a rare etiology of an autosomal recessive disorder. Endocr J. 2014;61:629-33.

9. Nguyen HH, Eiden-Plach A, Hannemann F, Malunowicz EM, Hartmann MF, Wudy SA, et al. Phenotypic, metabolic, and molecular genetic characterization of six patients with congenital adrenal hyperplasia caused by novel mutations in the CYP11B1 gene. J Steroid Biochem Mol Biol. 2016; 155(Pt A):126-34.

10. Sólyom RK, Péter F, Homoki J, Sippell WG, Peter M. Clinical, hormonal and molecular genetic characterization of Hungarian patients with $11 \beta$ hydroxylase deficiency. J Pediatr Endocrinol. 2001;2:37-44.

11. Holcombe JH, Keenan BS, Nichols BL, Kirkland RT, Clayton GW. Neonatal salt loss in the hypertensive form of congenital adrenal hyperplasia. Pediatrics. 1980;65:777-81.

12. Mimouni M, Kaufman H, Roitman A, Morag C, Sadan N. Hypertension in a neonate with 11ß-hydroxylase deficiency. Eur J Pediatr. 1985;143:231-3.

13. Parajes $\mathrm{S}$, Loidi $\mathrm{L}$, Reisch $\mathrm{N}$, Dhir $\mathrm{V}$, Rose IT, Hampel $\mathrm{R}$, et al. Functional consequences of seven novel mutations in the CYP11B1 gene: four mutations associated with nonclassic and three mutations causing classic 11ß-hydroxylase deficiency. J Clin Endocrinol Metab. 2010;95:779-88.

14. Zhang M, Liu Y, Sun S, Zhang H, Wang W, Ning G, et al. A prevalent and three novel mutations in CYP11B1 gene identified in Chinese patients with 11ß-hydroxylase deficiency. J Steroid Biochem Mol Biol. 2013;133:25-9.

15. Curnow KM, Slutsker L, Vitek J, Cole T, Speiser PW, New MI, et al. Mutations in the CYP11B1 gene causing congenital adrenal hyperplasia and hypertension cluster in exons 6, 7, and 8. Proc Natl Acad Sci U S A. 1993:90:4552-6.

16. Lopez-Bigas N, Audit B, Ouzounis C, Parra G, Guigo R. Are splicing mutations the most frequent cause of hereditary disease? FEBS Lett. 2005;579:1900-3.

17. Ward AJ, Cooper TA. The pathobiology of splicing. J Pathol. 2009;220:152-63.

18. Desviat $L R$, Pérez $B$, Ugarte M. Minigenes to confirm exon skipping mutations. Methods Mol Biol. 2012;867:37-47.

19. Scotti MM, Swanson MS. RNA mis-splicing in disease. Nat Rev Genet. 2016;17:19-32.

20. Gerstein MB, Rozowsky J, Yan KK, Wang D, Cheng C, Brown JB, et al. Comparative analysis of the transcriptome across distant species. Nature. 2014;512:445-8.

21. Merke DP, Tajima T, Chhabra A, Barnes K, Mancilla E, Baron J, et al. Novel CYP11B1 mutations in congenital adrenal hyperplasia due to steroid 11 $\beta$ hydroxylase deficiency. J Clin Endocrinol Metab. 1998;83:270-3.

22. Samaranch L, Lorenzo-Betancor O, Arbelo JM, Ferrer I, Lorenzo E, Irigoyen J, et al. PINK1-linked parkinsonism is associated with Lewy body pathology. Brain. 2010;133(Pt4):1128-42.

\section{Submit your next manuscript to BioMed Central and we will help you at every step:}

- We accept pre-submission inquiries

- Our selector tool helps you to find the most relevant journal

- We provide round the clock customer support

- Convenient online submission

- Thorough peer review

- Inclusion in PubMed and all major indexing services

- Maximum visibility for your research

Submit your manuscript at www.biomedcentral.com/submit 